\title{
Heterotopic Ossification after Cervical Arthroplasty with ProDisc-C: Time Course Radiographic Follow-up over 3 years
}

\author{
Yong-Hwan Cho', Keun-Su Kim², Young-Min Kwon ${ }^{1}$ \\ ${ }^{I}$ Department of Neurosurgery, Dong-A University College of Medicine, Busan, Korea \\ ${ }^{2}$ Department of Neurosurgery, Spine and Spinal Cord Institute, Gangnam Severance Spine Hospital, Yonsei University \\ College of Medicine, Seoul, Korea
}

\begin{abstract}
Objective: Heterotopic ossification $(\mathrm{HO})$ is a well-known complication after total hip replacement. But the occurrence rate by the time-course, clinical effect and risk factors of $\mathrm{HO}$ after total cervical disc replacement (TCDR) are not well described. The purpose of this study is to evaluate the occurrence rate by the time-course and risk factors for HO after TCDR with a ProDisc-C.

Methods: Thirty-two patients whom followed up more than one year after the TCDR are enrolled. Radiographic study was done at 12, 24 and 36 months after the TCDR and classified HO with McAfee classification. Segmental range of motion, preoperative existence of spondylosis, type of operation, disc space occupying ratio by artificial disc, surgical level are analyzed to identify the risk factors of $\mathrm{HO}$. The visual analog scale and the neck disability index were evaluated preoperatively and at last follow-up time for clinical parameters.

Results: Eighteen patients (56\%) showed HO at 12 months, 18 patients (86\%) showed HO at 24 months and 6 patients (89\%) showed $\mathrm{HO}$ at 36 months after the TCDR. Clinical significant $\mathrm{HO}$ (Grade 3 and 4) was shown in one patient (3\%) at 12 months, 3 patients (14\%) at 24 months and 5 patients $(56 \%)$ at 36 months. Only post-operative follow-up period increases the risk of development clinical significant $\mathrm{HO}$. All patients showed improvement of clinical parameters $(p<0.005)$.

Conclusion: Incidence of $\mathrm{HO}$ is getting higher as time course progress. However, there are no relation between clinical outcome and radiologic change of ROM and the grade of $\mathrm{HO}$.
\end{abstract}

Key Words: Heterotopic ossification $\cdot$ Total disc replacement $\cdot$ Cervical arthroplasty

\section{INTRODUCTION}

Anterior cervical discectomy and fusion (ACDF) is golden standard for treatment of cervical degenerative disc disorders with a long term clinical success ${ }^{7,19)}$. Although ACDF shows the excellent clinical and radiologic outcomes, it may leads to symptomatic adjacent segment degeneration. According to Hillbrand et al. ${ }^{10)}$ symptomatic new disease occurred at an adjacent level at the relatively constant incidence of 2.9 percent per year in the ten years after the operation. In addition, within 10 years, up to $25 \%$ of all patients treated with ACDF

- Received: February 13, 2013 • Revised: March 23, 2013

- Accepted: March 24, 2013

Corresponding Author: Young-Min Kwon, MD

Department of Neurosurgery, College of Medicine, Dong-A University

Hospital, Dongdaesin-dong 3 ga, Seo-gu, Busan 602-715, Korea

Tel: +82-51-240-5241, Fax: +82-51-242-6714

E-mail: ymkwon@dau.ac.kr may have symptomatic adjacent segment disc degeneration. Increased longitudinal or shear strain after ACDF contribute adjacent segment disc degeneration ${ }^{16}$. Recent study suggested that total cervical disc replacement (TCDR) can be alternative treatment option ${ }^{20)}$. TCDR preserve disc joint mobility and restore disc height, which is considered to prevent adjacent level degeneration. However, in terms of incidence of adjacent level degeneration, it is unclear that TCDR have clinical advantage.

Heterotopic ossification (HO) is well known complication after total hip arthroplasty ${ }^{4,13,23)}$. HO and spontaneous fusion in patient treated with TCDR have been reported. According to Mehren et al. ${ }^{18)}$, Grade III HO was observed in $10.4 \%$, and Grade IV HO was observed in 9.1\% of the implanted cases in a 1 year follow up. But the occurrence rate by the timecourse, clinical effect and risk factors of $\mathrm{HO}$ after total cervical disc replacement (TCDR) are not well described.

We designed this study to analyze the occurrence rate by the time-course and possible risk factors for $\mathrm{HO}$ after the TCDR with a ProDisc-C. 


\section{MATERIALS AND METHODS}

From September, 2005 to October, 2008, 48 patients underwent TCDR with a ProDisc-C (Synthes, Inc., West Chester, PA) by one surgeon and 32 patients whom followed up more than one year after the operation are enrolled in this study. Clinical and radiologic data of these 32 patients were retrospectively reviewed.

TCDR was performed by standard anterior cervical approach and microdiscectomy was done, but the posterior longitudinal ligament was retained as much as possible. Meticulous hemostasis of soft-tissue bleeding was done and bone bleeding was controlled with a bone wax before insertion of artificial disc. Patients with degenerative disc herniation with no or minor spondylosis between $\mathrm{C} 3 / 4$ and $\mathrm{C} 6 / 7$ were included. Exclusion criteria were segmental instability, severe spondylosis, ossification of posterior longitudinal ligament and severe disc height loss.

Radiographic and clinical evaluation was done at 12 months, 24 months and 36 months after the TCDR. Routine cervical anteroposterior (AP), lateral, dynamic views were taken to identify $\mathrm{HO}$. Classification of $\mathrm{HO}$ was done according to modified McAfee classification that are proposed by Mehren et $\mathrm{al}^{18)}$. The classification has 5 -points grade: grade $0=$ no $\mathrm{HO}$

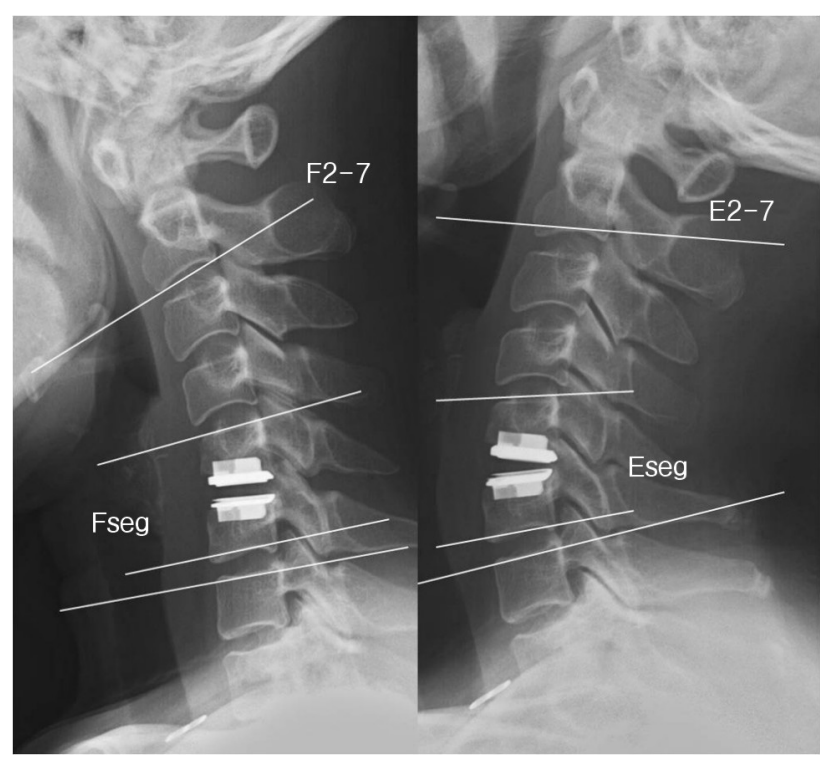

Fig. 1. Illustration of segmental range of motion (SROM) measurement. SROM was measured using dynamic flexion and extension image. Fseg=segmental cobb's angle of implanted disc space in flexion view, Eseg=segmental cobb's angle of implanted disc space in extension view, F2-7 and E2-7=cobb's angle between lower margin of C2 body and upper margin of C7 body. SROM $=(\text { Fseg }+ \text { Eseg } / \text { F2-7 }+ \text { E2-7 })^{*} 100$ present; grade $1=$ presence of $\mathrm{HO}$ but not in the interdiscal space; grade $2=$ presence of $\mathrm{HO}$ in the interdiscal space; grade 3 =bridging of ossification with segment movement; grade $4=$ complete fusion without movement in flexion/extension. We also defined $\mathrm{HO}$ grade above 2 ( $\mathrm{HO}$ grade 3 and 4 ) as a clinical significant $\mathrm{HO}$.

To evaluate risk factors of $\mathrm{HO}$, patient's age, sex, follow up period, segmental range of motion (ROM), preoperative existence of spondylosis, type of operation (TCDR vs hybrid operation), disc space occupying ratio by artificial disc, operation level, number of surgical level (single level vs multi-level) and pre-operative disc grade were analyzed. Pfirrmann's lumbar disc degeneration grade was used to evaluate pre-operative disc grade $^{22}$. On the pre-operative flexion/extension view, segmental ROM was checked. Segmental ROM was calculated by ratio of summation of Cobb's angles of implanted disc space per summation of Cobb's angles between $\mathrm{C} 2$ and $\mathrm{C} 7$ on flexion and extension view (Fig. 1). Cobb's angle of implanted disc space was measured between upper parallel end plate line of upper vertebral body and lower parallel end plate line of lower vertebral body of implanted disc. Lordosis angle was expressed as positive, whereas kyphosis angle was expressed as negative. Disc space occupying ratio by artificial disc was evaluated as a ratio to anteroposterior diameter of the vertebral body and length of ProDisc-C in disc space (Fig. 2). Pre-operative existence of spondylosis was identified on both simple X-ray and cervical computed tomography (CT).

For clinical parameters, the visual analog scale (VAS) and the neck disability index (NDI) were evaluated preoperatively and at the time of the last follow-up.

Statistical analysis was done using chi square test and multiple logistic regression tests. All $\mathrm{p}$ values less than 0.05 were considered statistically significant.

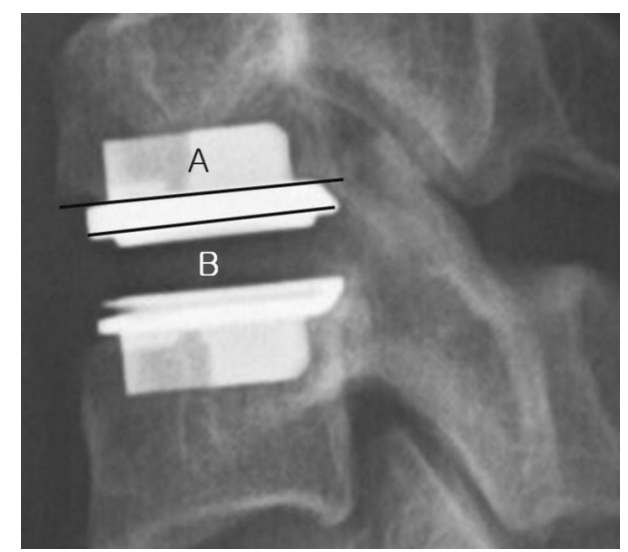

Fig. 2. Disc space occupying ratio by artificial disc was measured using simple $X$-ray lateral image. Occupying ratio $=B / A^{*} 100 ; A$ : anteroposterior diameter of vertebral body; $\mathrm{B}$ : anteroposterior diameter of artificial disc. 


\section{RESULTS}

The group consisted of 25 men and 7 women and their average age of all patients was 41.7 years (range 27-67 years). Total of thirty two patients were followed at least 1 year, 21 patients for 2 years and 12 patients for 3 years. Five patients (15.6\%) underwent hybrid operation (combined TCDR and ACDF). A single level surgery was performed in 27 patients (84.4\%), two levels (hybrid operation) in $3(9.3 \%)$ and three levels (hybrid operation) in 2 patients (6.3\%). Total 34 ProDisc-C prostheses were implanted, the $\mathrm{C} 3 / 4$ intervertebral disc was replaced in 1 (2.9\%), C4/5 in 5 (14.7\%), C5/6 in $38(59 \%)$ and

Table 1. Demographic of patients

\begin{tabular}{lc}
\hline \hline Number of patients & 32 \\
Sex (Male : Female) & $25: 7$ \\
Mean Age (Range) & $41.7(26-67)$ \\
Operated level & \\
C3/4 & $1(2.9)$ \\
C4/5 & $5(14.7)$ \\
C5/6 & $22(64.7)$ \\
C6/7 & $6(17.7)$ \\
Total number of implants & 34 \\
Type of operation & \\
TCDR & $27(84.4)$ \\
TCDR + Fusion & $5(15.6)$ \\
Single level surgery & $27(84.4)$ \\
Two-level surgery & $3(9.3)$ \\
Three-level surgery & $2(6.3)$ \\
\hline
\end{tabular}

Table 2. Risk factors for heterotopic ossification according to various parameters

\begin{tabular}{|c|c|c|c|}
\hline Factors & Odd ratio & $\begin{array}{c}95 \% \text { confidential } \\
\text { interval }\end{array}$ & p-value \\
\hline Sex (female vs. male) & 1.176 & (0.186-7.427) & $0.624^{*}$ \\
\hline $\operatorname{Age}(<50$ vs. 50$)$ & 0.238 & $(0.025-2.264)$ & $0.193^{*}$ \\
\hline $\begin{array}{l}\text { Type of op surgery } \\
\text { (TCDR vs. Hybrid) }\end{array}$ & 0.630 & $(0.471-0.841)$ & $0.131^{*}$ \\
\hline $\begin{array}{l}\text { Disc grade } \\
\text { (Pfimann's grade } 2 \text { vs. 3) }\end{array}$ & 1.500 & (0.329-6.833) & $0.445^{*}$ \\
\hline $\begin{array}{l}\text { Number of surgical level } \\
\text { (Single level vs. multi-level) }\end{array}$ & 0.704 & (0.551-0.899) & $0.691^{*}$ \\
\hline $\begin{array}{l}\text { Spondylosis } \\
\text { (existence vs. non-existence) }\end{array}$ & 2.769 & (0.473-16.213) & $0.229^{*}$ \\
\hline Occupying ratio & $\mathrm{N} / \mathrm{A}$ & $\mathrm{N} / \mathrm{A}$ & $0.643^{+}$ \\
\hline Segmental ROM & $\mathrm{N} / \mathrm{A}$ & $\mathrm{N} / \mathrm{A}$ & $0.540^{+}$ \\
\hline
\end{tabular}

"Analyzed by chi-square test, ${ }^{+}$Analyzed by multiple regression test, N/A: Not available
C6/7 in 6(17.7\%). Fifteen patients (47\%) showed pre-operation disc grade 3 and the others in 4 (Table 1 ).

At 12 month follow-up, eighteen patients (56\%) showed $\mathrm{HO}$ and one patient (3\%) showed clinical significant HO. At 24 months follow up, 18 patients (86\%) showed $\mathrm{HO}$ and significant $\mathrm{HO}$ was shown in 3 patients (14\%). At 36 months follow up, 11 patients (91.7\%) showed $\mathrm{HO}$ and 5 patients (41.7\%) presented clinical significant $\mathrm{HO}$ (Fig. 3 and 4). As far as 36 months followed up, there was no grade IV HO.

No association was found between the development of $\mathrm{HO}$ and assessed risk factors. Patient's age $(p=0.624)$, sex $(p=0.193)$, existence of spondylosis $(\mathrm{p}=0.229)$, pre- and post-operative $\operatorname{ROM}(p=0.540)$, number of surgical level $(p=0.691)$, disc space occupying ratio by artificial disc $(\mathrm{p}=0.643)$, type of operation $(p=0.131)$, disc grade $(p=0.445)$ and operation level $(p=$ 0.691 ) were not related to the risk factors for formation of

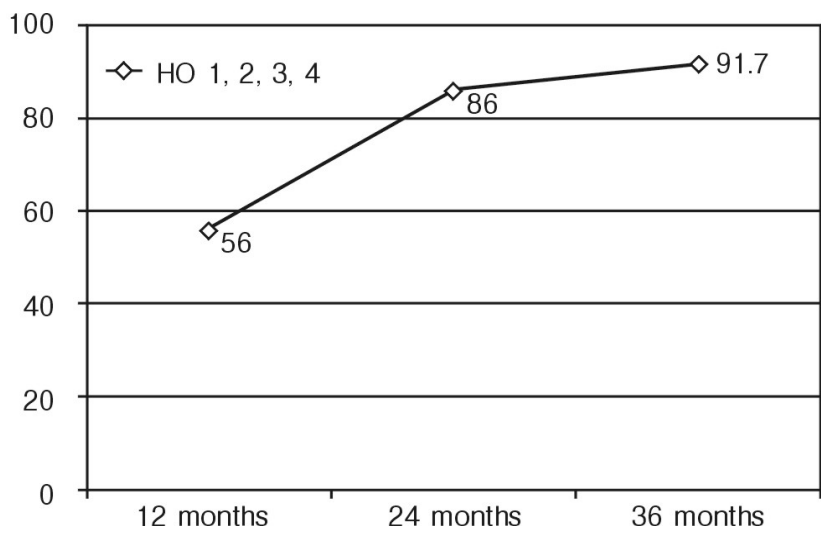

Fig. 3. Occurrence rate of $\mathrm{HO}$ by postoperative period (\%). Total $56 \%$ of patients showed $\mathrm{HO}$ at 12 months while $86 \%$ at 24 months and $91.7 \%$ at 36 months showed $\mathrm{HO}$ after TCDR.

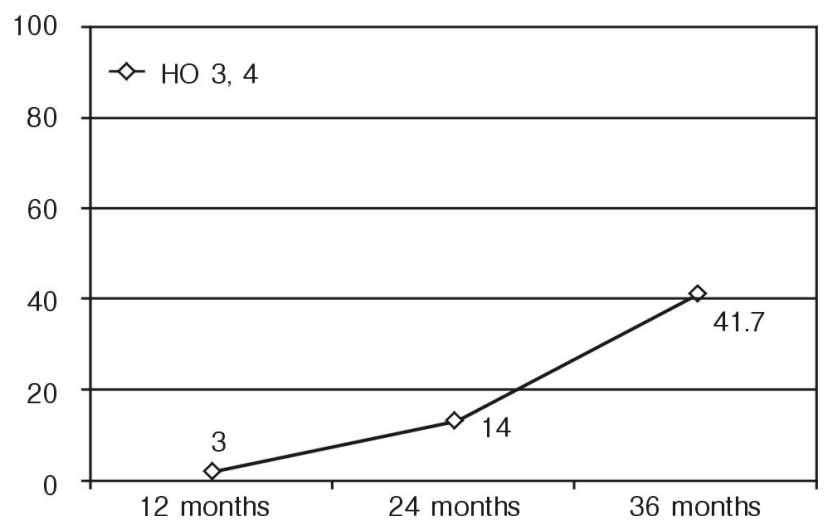

Fig. 4. Clinical significant $\mathrm{HO}$ by postoperative period (\%). Three percent of patients showed clinical significant $\mathrm{HO}$ at 12 months, $14 \%$ at 24 months and $41.7 \%$ at 36 months after TCDR. Longer period after operation increase risk of clinical significant $\mathrm{HO}$ $(p=0.043)$. 


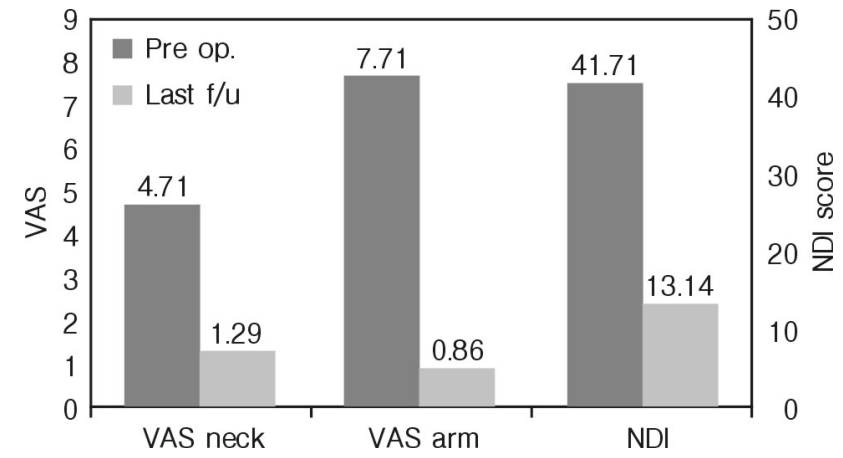

Fig. 5. VAS arm and VAS neck at pre-op time and last follow-up time, and NDI at pre-op time and last follow-up time. Both clinical parameters were improved at last follow-up time $(p<0.05)$.

HO (Table 2). However, post-operative follow-up period was the only statistically significant factor that showed formation of $\mathrm{HO}$ after TCDR ( $\mathrm{p}=0.043$ ) (Fig. 4). Preoperative NDI was improved from 41.71 to 13.41 at last follow up, mean VAS in neck pain decreased from 4.71 preoperatively to 1.29 at last follow-up time, and VAS in arm pain decreased from 7.71 to 0.86 at last follow-up time (Fig. 5).

\section{DISCUSSION}

Both traditional ACDF and TCDR show good clinical outcome. And a few randomized controlled studies demonstrated a better clinical outcome in the group of TCDR than the groups of $\mathrm{ACDF}^{5,24}$. Potential benefit of TCDR is maintaining of segmental motion to preserve physiological ROM. And moreover theoretically TCDR reduce the adjacent segment disease. Some studies showed that fusion increase the motion and intradiscal pressure at the adjacent segment while arthroplasty did not $8,9,26$. However, a few studies have been reported the $\mathrm{HO}$ as complication of the TCDR and even more fusion has been reported after the $\mathrm{TCDR}^{1,21)}$.

Various range of occurrence rate of $\mathrm{HO}$ after TCDR have been reported. Occurrence rate of $\mathrm{HO}$ at 12 months after surgery ranged from 17.8 to $72.3 \%$ while clinical significant HO showed range of 4.2 to $23.1 \%$. At 24 months after the surgery showed $28.8 \%$ to $78.5 \%$ of occurrence rate of $\mathrm{HO}$ and $8.5 \%$ to $32.3 \%$ range of clinical significant occurrence rate of $\mathrm{HO}^{14,15,18,25,28)}$. Pooled prevalence of $\mathrm{HO}$ was $44.6 \%$ at 12 months and $58.2 \%$ at 24 months after TCDR, while clinical significant $\mathrm{HO}$ was $11.1 \%$ and $16.7 \%$ respectively ${ }^{6}$. Our series showed higher occurrence rate of $\mathrm{HO}$ at 12 and 24 months after TCDR than previously reported article, but similar occurrence rate of clinical significant $\mathrm{HO}$ is shown. However, $\mathrm{HO}$ was evaluated only on the simple plain X-ray in our study. If the existence of $\mathrm{HO}$ was evaluated on cervical
CT, a higher incidence of $\mathrm{HO}$ might be reported ${ }^{3)}$. However, there were no grade $4 \mathrm{HO}$ at the 36 months after TCDR so far, but grade 4 could be seen if the longer post-operative period is followed.

Many studies about relationship between HO and TCDR have been reported. Various clinical factors have been suggested as risk factors for HO. According to Leung et al. ${ }^{15)}$ male sex and older age were associated with development of $\mathrm{HO}$. In our series neither sex nor old age did not increase occurrence rate of $\mathrm{HO}$. Other studies demonstrate a higher rate of $\mathrm{HO}$ formation in patient with spondylosis or degenerative change than in those with a soft-disc herniation ${ }^{3,27}$. Our study also tried to see the relationship between $\mathrm{HO}$ formation and degree of pre-operative degeneration. Therefore we evaluated pre-operative disc grade using Pfirmann's grade ${ }^{22)}$ and pre-operative existence of spondylosis using cervical CT. However, we exclude severe spondylosis and disc height loss patients, and it may make difference in result. Removal of posterior osteophyte is mandatory for patients with cervical spondylosis. Remained bone dust after removal of osteophyte may promote formation of HO. We minimized drilling of posterior osteophyte and retained posterior longitudinal ligament as much as possible.

Yi et al. ${ }^{28)}$ suggested different types of prosthesis shows different occurrence rate of $\mathrm{HO}$ may be due to different biomechanical mechanism of prosthesis types. To avoid the effect of biomechanics and biomaterial of prosthesis device to formation of $\mathrm{HO}$, we restricted to one type of artificial disc. They proposed that well fitting prosthesis device in AP diameter could prevent formation of HO. We measured disc space occupying ratio by artificial disc on immediate post-operative simple X-ray. Either increased or decreased pre-operative segmental ROM may act as a risk factor for formation of HO. However, our series showed that there were no relations between $\mathrm{HO}$ occurrence rate and both clinical factors. Mehren et al. ${ }^{18)}$ reported higher rate of $\mathrm{HO}$ in multi-level case than mono-level case. However, our series shows no differences but very limited number of cases of multi-level TCDR was enrolled. There were no clinical parameters that are related to occurrence of HO. So far, only the longer post-operative period increase the risk of $\mathrm{HO}$ in this study. That may be due to as normal physiologic compensation to iatrogenic instability which was induced by removing of both anterior and posterior longitudinal ligament and some part of uncinate process.

There were no correlation between formation of $\mathrm{HO}$ and clinical outcome. In this study, there was good clinical improvement in the VAS, NDI. Some studies have reported that $\mathrm{HO}$ is less important in the absence of clinical deterioration $^{2,12)}$. Until now, there is no evidence that whether all $\mathrm{HO}$ finally progressed spontaneous fusion. And also recent study 
demonstrated that TCDR does not prevent development of adjacent segment disease ${ }^{11)}$. However, decreased motion on TCDR segment from HO is the complication of TCDR and against the fundamental goal of TCDR.

There were some limitations in our study. The more cases are needed, and all patients should be followed same period and longer follow-up study should be followed. We analyzed risk factors could affect $\mathrm{HO}$ formation. Although no clinical association was founded, we expect this result could help decision making of performing TCDR.

\section{CONCLUSION}

Relatively high incidence of $\mathrm{HO}$ was shown and about 42\% of clinical significant $\mathrm{HO}$ was shown at 36 months after the TCDR. However, there was no complete fusion in this study. In terms of clinical improvement, TCDR is comparable to ACDF. Clinical improvement was not correlated with grade of $\mathrm{HO}$ and radiologic change of ROM. HO formation risk was not correlated with clinical parameters. Only longer postoperative period increase the risk of $\mathrm{HO}$ formation.

\section{REFERENCES}

1. Bartels RH, Donk R: Fusion around cervical disc prosthesis: case report. Neurosurgery 57:E194, 2005

2. Bertagnoli R: Heterotopic ossification at the index level after Prodisc-C surgery: what is the clinical relevance? Spine J 8:123S, 2008

3. Brenke C, Scharf J, Schmieder K, Barth M: High prevalence of heterotopic ossification after cervical disc arthroplasty: outcome and intraoperative findings following explantation of 22 cervical disc prostheses. J Neurosurg Spine 17:141-146, 2012

4. Brooker AF, Bowerman JW, Robinson RA, Riley LH Jr.: Ectopic ossification following total hip replacement. Incidence and a method of classification. J Bone Joint Surg Am 55:1629-1632, 1973

5. Burkus JK, Haid RW, Traynelis VC, Mummnaneni PV: Longterm clinical and radiographic outcomes of cervical disc replacement with the Prestige disc: results from a prospective randomized controlled clinical trial. J Neurosurg Spine 13:308-318, 2010

6. Chen J, Wang X, Bai W, Shen X, Yuan W: Prevalence of heterotopic ossification after cervical total disc arthroplasty: a metaanalysis. Eur Spine J 21:674-680, 2012

7. Cherry C: Anterior cervical discectomy and fusion for cervical disc disease. AORN J 76:998-1004,2002

8. DiAngelo DJ, Roberston JT, Metcalf NH, McVay BJ, Davis RC: Biomechanical testing of an artificial cervical joint and an anterior cervical plate. J Spinal Disord Tech 16:314-323, 2003

9. Eck JC, Humphreys SC, Lim TH, Jeong ST, Kim JG, Hodges SD, et al: Biomechanical study on the effect of cervical spine fusion on adjacent-level intradiscal pressure and segmental motion.
Spine 27:2431-2434, 2002

10. Hillbrand AS, Carlson GD, Palumbo MA, Jones PK, Bohlman $\mathrm{HH}$ : Radiculopathy and myelopathy at segments adjacent to the site of a previous anterior cervical arthrodesis. J Bone Joint Surg Am 81:519-528, 1999

11. Horrod CC, Hilibrand AS, Fischer DJ, Skelly AC: Adjacent segment pathology following cervical motion-sparing procedure or device compared with fusion surgery: a systematic review. Spine 37:S96-S112, 2012

12. Janssen M, Goldstein J, Murrey D, Delamarter: Heterotopic ossifiction at the index level after Prodisc-C: What is the clinical significance? Spine J 7:48S-49S, 2007

13. Kjaersgaard-Andersen P, Schmidt SA: Total hip arthroplasty. the role of antiinflammatory medications in the prevention of heterotopic ossification. Clin Orthop Relat Res 263:78-86, 1991

14. Lee JH, Jung TG, Kim HS, Jang JS, Lee SH: Analysis of the incidence and clinical effect of the heterotopic ossification in a single-level cervical artificial disc replacement. Spine J 10:676682, 2010

15. Leung C, Casey AT, Goffin J, Kehr P, Liebig K, Lind B, et al: Clinical significance of heterotopic ossification in cervical disc replacement: a prospective multicenter clinical trial. Neurosurgery 57:759-763, 2005

16. Matsunaga S, Kabayama S, Yamamoto T, Yone K, Sakou T, Nakanishi K: Strain on intervertebral discs after anterior cervical decompression and fusion. Spine 24:670-675, 1999

17. McAfee PC, Cunningham BW, Devine J, Williams E, Yu-Yahiro $\mathrm{J}$ : Classification of heterotopic ossification $(\mathrm{HO})$ in artificial disk replacement. J Spinal Disord Tech 16:384-389, 2003

18. Mehren C, Suchomel P, Grochulla F, Barsa P, Sourkova P, Hradil J, et al: Heterotopic ossification in total cervical artificial disc replacement. Spine 31:2802-2806, 2006

19. Miller LE, Block JE: Safety and effectiveness of bone allografts in anterior cervical discectomy and fusion surgery. Spine 36: 2045-2050, 2011

20. Park JH, Hwang SW, Jeon SR, Rhim SC, Roh SW: Total cervical disc replacement using artificial disc in cervical disc herniations. Korean J Spine 5(1):1-6, 2008

21. Parkinson JF, Sekhon LH: Cervical arthroplasty complicated by delayed spontaneous fusion: case report. J Neurosurg Spine 2:377-380, 2005

22. Pfirrmann CW, Metzdorf A, Zanetti M, Hodler J, Boos N: Magnetic resonance classification of lumbar intervertebral disc degeneration. Spine 26:1873-1878, 2001

23. Ritter MA, Vaughan RB.: Ectopic ossification after total hip arthroplasty. predisposing factors, frequency, and effect on results. J Bone Joint Surg Am 59:345-351, 1977

24. Sasso RC, Anderson PA, Riew KD, Heller JG: Results of cervical arthroplasty compared with anterior discectomy and fusion: fouryear clinical outcomes in a prospective, randomized controlled trial. J Bone Joint Surg Am 93:1684-1692, 2011

25. Suchomel P, Jurák L, Benes V $3^{\text {rd }}$, Brabec R, Bradác O, Elgawhary S: Clinical results and development of heterotopic ossification in total cervical disc replacement during a 4-year follow-up. Eur Spine J 19:307-315, 2010

26. Wigfield CC, Skrzypiec D, Jackowski A, Adams MA: Internal stress distribution in cervical intervertebral discs: the influence of an artificial cervical joint and simulated anterior interbody 
fusion. J Spinal Disord Tech 16:441-449, 2003

27. Wu JC, Huang WC, Tu TH, Tsai HW, Ko CC, Wu CL, et al: Differences between soft-disc herniation and spondylosis in cervical arthroplasty: CT-documented heterotopic ossification with minimum 2 years of follow-up. J Neurosurg Spine 16:163-171,
2012

28. Yi S, Kim KN, Yang MS, Yang JW, Kim H, Ha Y, et al: Difference in occurrence of heterotopic ossification according to prosthesis type in the cervical artificial disc replacement. Spine 35:1556-1561, 2010 